\title{
FIRST AID MATTERS: DEVELOPING INTERPROFESSIONAL COMPETENCIES BY REMOTE LEARNING
}

\author{
Lucio-Ramirez CA*, Trevino-Alanis CA, Gomez-Gutierrez AK, \\ Turrubiates-Corolla ML, Valencia-Castro JL and Olivares-Olivares \\ SL \\ Tecnologico de Monterrey, Escuela de Medicina y Ciencias de la Salud, Mexico
}

\begin{abstract}
First aid training is a fundamental requirement for healthcare programs. For Tec21, there is a week dedicated to educating students in this topic. The COVID-19 pandemic forced the faculty team to redesign the First Aid Week from face-to-face training into a remote learning practice. The purpose was to assess the perceived value of competencies learning, considering first aid emergency skills and interprofessional working. The method was mixed: quantitative with pre-test and post-test (Cronbach alpha 0.93 and 0.97 ) and qualitative analysis. The difference between expectations (pre-test) vs. achievements(post-test) was analyzed with Expectation Confirmation Theory (Olivares $e t$ al., 2019), which classifies results as positive confirmation (+DC), confirmation (C), and negative confirmation (-DC). A total of 253 students participated from Physician and Surgeon, Nutrition and Wellness, Dentistry, Psychology, and Biosciences. Twelve items were related to accident preventive teaching, basic life support, psychological first aid, role designation, and teamwork communication. Day one was about introduction and prevention. On day two, students learned about triage and self-directed group simulation. Third day included a CPR practice (using a DIY mannequin). On day four, students had lectures on psychological first aid and a role-playing activity with peers and instructors. Results indicated $+\mathrm{DC}$ on both competencies. Knowledge in practice was $3.34( \pm 1.13)$ (pre-test) and $4.84( \pm 0.57)$ (post-test) with a p-value of <.0001. Ethical practice and reflection were $4.40( \pm 0.46)$ (pre-test) and $4.15( \pm 0.62)$ (post-test) with a p-value of 0.025 . Interprofessional working was $4.53( \pm 0.52)$ (pre-test) and $4.77( \pm 0.49)$ (post-test) with a pvalue of $<.0001$. The most common feedback from students was that they learned how to respond in an emergency. Interprofessional Healthcare Education promotes collaboration to enhance the quality of patient care. The distance teaching format was not a barrier to learning. The lack of commercial mannequins was replaced with low-cost simulation activity from home. This innovative immersive week helped students learn about first aid and increase their ability to respond to basic emergencies.
\end{abstract}

Keywords: First aid, remote learning, competencies learning, interprofessional and remote training

\section{Introduction}

\section{Relevance of Interprofessional First Aid Training}

First aid training is a fundamental requirement for health professionals. First aid is defined as providing emergency care to an injured individual, usually outside of the hospital and without any special equipment (Tan et al., 2010). No matter at which point of their undergraduate formation they 
are, the community expects healthcare students to know how to act in an emergency situation and have basic first aid and resuscitation skills (Perkins et al., 1999). In addition to the public's expectations, medical and health sciences students have the professional duty of knowing how to basic emergency care to people in need (Magnavita et al., 2020). Medical and health sciences programs should include first aid and basic life support (BLS) training for their students early off in their curriculums (Tan et al. 2006).

As stated by the World Health Organization (WHO) in 2010, educational institutions have been encouraged to incorporate the development of Interprofessional Education (IPE) and collaborative practice. Khabaz et al (2016) define IPE when two or more professionals learn from and about one another to encourage collaboration in practice. Hence, it is argued that the best care would be delivered as a multidisciplinary team. This is a fundamental skill needed in the healthcare system in which every member has a unique expertise that they could share to collaborate effectively to improve patient care outcomes.

Gordon and Walsh (2005) developed an Interprofessional Capability Framework with four domains that represent the working purposes of interprofessional learning. These four domains are: knowledge in practice, ethical practice, interprofessional working and reflection (learning). Each one of the domains has a specific purpose and it serves as a guide for students to achieve interprofessional capability. Knowledge in practice refers to the awareness of other professions within the interprofessional team and its functions in context, in this specific case the context would be first aid training. Ethical practice focuses on the students' participation in the decision-making process of the team and on developing sensibility. Interprofessional working focuses on communication strategies and on successful interprofessional teams The Reflection (learning) domain promotes reflection as a way to consolidate and integrate knowledge and professional development. Becoming an interprofessional worker is a complex task but using this framework as a guideline is a good place to start. Taking this into consideration, which interprofessional competencies can students develop during a first aid training program?

Several examples worldwide can illustrate how basic first aid training can be approached in health professions students. The University of Birmingham in the United Kingdom modified and improved its BLS training for students. Students practiced their practical skills after a brief lecture on the topic. Ninety-nine percent of students required only one attempt to complete their end-of-course assessment successfully, and a high proportion of them reported confidence in doing so (Perkins et al.,1999). In a study done in the Netherlands, seven out of 8 universities had BLS training as part of their curriculum (Tan et al., 2010). In most of them, the training was delivered in the 1st or 2 nd year of formation. All of them used training equipment during the lessons: either mannequins, first aid kit, a mouth mask, or an automated external defibrillator. 50\% of programs used simulated patients. Both studies recommend that BLS training be held during the first year of the medical curriculum and reinforced years later. They both agree that hands-on practice is more attractive and practical for students to retain their knowledge and improve their confidence.

In addition to learning and having the opportunity to reinforce knowledge in the years to come, one of the most common complaints in first-year health sciences students is that very little of what they learn seems to be relevant (Nelson, 1982). Even though they are in their initial training, they already feel 
like health professionals and are eager to learn, practice, and feel useful. This hands-on training is an opportunity for them to feel like actual health providers in training and to start developing their practical and clinical skills. Besides, it is an efficient way to increase awareness about first aid's importance (Pande et al., 2014). If students share their recently acquired knowledge with friends and family, an important part of the community will be aware of first aid basics and might look into proper training. In our institution, we acknowledge the importance of cardiopulmonary resuscitation (CPR) training as a fundamental set of skills in medical students. Nowadays, it is a requirement for students to start clinical clerkships since they become an important part of the delivery-care team.

In addition to the skills health sciences, students gain during first aid training, another important component is building trust and confidence. One of the most critical determinants of survival from sudden cardiac arrest is a well-trained and motivated rescuer (Pande et al. 2014). During training, instructors may use lectures, videos and demonstrations. However, it is fundamental that students have the chance to practice their learned skills with a hands-on approach using either mannequins, role-playing or simulated patients (Das and Elzubeir, 2001). Furthermore, the skills they acquire must be reassessed further during their academic formation. Lack of practice could lead to a decrease in retention of knowledge and clinical skills.

Accident and emergency prevention is the most effective way of saving preventable deaths. Each year, there are around 950000 deaths of children and young adults due to violence and injuries. Additionally, there are thousands of children that require medical attention at a hospital because of non-fatal injuries. Most of the time, these accidents or injuries are preventable. Some developed countries, like Sweden, have managed to decrease their mortality rates from injuries by about $50 \%$. Some of these countries' prevention strategies are new legislation, product modification, child-proof environment, security devices, education, community projects, and emergency care (WHO, 2008).

TRIAGE is a system of classification used to prioritize patient attention when there are many patients in need of help. The purpose of triage is to save as many lives as possible, and the people in charge have to decide which patients would benefit the most from immediate attention, treatment, and transport. In cases of a mass-casualty incident, when there might not be enough medical staff, aid from non-medical volunteers might be needed, which is why health-sciences students should be trained to do so. The University of North Carolina evaluated the accuracy of triage decisions made by newly enrolled first-year medical students after receiving a brief lecture on START triage training. (Sapp et al., 2010). Their results showed that after a short lecture, the students achieved accuracy scores very similar to physicians, nurses, and paramedics. A university in Novarra, Italy (Universita degli Studi del Piemonte Orientale' A. Avogadro') did research to compare virtual reality vs life simulation triage. It proved that virtual reality is a precious tool. It is cost-effective and equivalent to live simulation in testing students' abilities to perform a triage training simulation. (Ingrassia et al., 2015)

Before the CPR era, high mortality rates were observed in patients undergoing cardiac arrest. The introduction of CPR training has proved a life-saving skill that needs to be instructed to all healthcare professionals. Training includes lectures and hands-on practice on airway control, mouth-to-mouth breathing, chest compressions, and how to activate the life support chain (Eisenburger and Safar, 1999). 
Psychological first aid (PFA) is defined as a "humane, supportive response to a fellow human being who is suffering and who may need support" (Minihan et al., 2020). The importance of psychological first aid should be acknowledged and promoted as medical first aid (Canady, 2019). Rescuers can be trained and ready to support any person suffering from distress during an emotional crisis. The rescuer's role is to be supportive, listen actively, and recognize that the patient may or may not want help, and give support and comfort to the person in need (Minihan et al., 2020). In light of the COVID19 pandemic, many people have been living with fear, panic, anxiety, isolation, and uncertainty (Shah et al., 2020). It is essential to have trainees ready to give these people the aid they might need during these times.

\section{Current context}

The COVID19 pandemic has challenged medical institutions to build strategies to assure the completion of medical students' curricula (Gonzales Zamora et al., 2020; Mian and Khan, 2020). In this regard, the transition from face-to-face medical care to remote education models has occurred using tools like video conferencing, telehealth services, and smartphone applications. For example, Gonzáles-Zamora et al. (2020) developed a program based on video conferences as an educational tool for teaching about infectious diseases in a cluster of four various hospitals. A recently published systematic review showed that there have been several approaches to giving virtual consults to reinforce medical residents' training of surgery, dermatology, and rheumatology (Dedeilia et al., 2020). In Latin America, Dominguez-Cherit et al. (2021) developed a program for training physicians to manage critically ill COVID19 patients by using a hybrid model of face-to-face and remote instruction. These interventions have a high acceptance rate from students in a common way, reduction of mobility, re-engagement of students in the direct care of patients, and the possibility of massive training. As mentioned earlier, CPR training represents a requirement for medical students in the pre-clinical setting to advance to clinical clerkships. Due to COVID19 pandemic restrictions, there have been several obstacles in achieving high-quality CPR practice.

To the extent of our knowledge, only a few strategies have been published to address the reduction of first aid training courses due to the COVID19 pandemic. For example, to meet these needs, Harkins (2020), developed an online, 30-minute CPR program using a videoconference platform in the early months of the pandemic. In this course, participants learned the fundamental methods and meaning of life-saving hands-only CPR. At the end of the course, the students were offered a CPR kit, which includes a small mannequin and video they can use to train others. Also, Non-Profit organizations such as "Save a Life" by National Healthcare Provider Solutions (NHCPS) have created online courses directed to train both BLS and Advanced Cardiovascular Life Support (ACLS). To ensure understanding of all concepts, students could go back, rewatch, reread, and retest (NHCPS, 2020). However, these interventions have limitations such as reducing hands-on training, lack of collaborative learning, and communication skills, which are fundamental competencies in every rescuer.

Considering the importance of integrating the abilities given by first aid training and the limitations of the strategies mentioned above, we re-designed the First Aid Week. This approach consisted of a series of remote activities involving accident prevention, TRIAGE, BLS, and psychological first aid. This study aimed to evaluate this strategy's impact in terms of theoretical knowledge acquisition, first 
aid skills execution, and communication abilities. In this article, we describe the pathway for developing this intervention and its implementation in a cohort of Mexican medical and health sciences students.

\section{Methods}

\section{Subjects}

A total of 253 students participated during First Aid Week. Medical, Nutrition, Dentistry, Clinical Psychology, and Bioscience's students were involved in this immersive learning experience. All students were adults between 18 and 20 years of age. The purpose was to assess the perceived value of competencies learning, considering first aid emergency skills and collaboration. Due to COVID19 restrictions, all the activities were designed to happen remotely via a video conference platform.

\section{Intervention}

The first day of the week revolved around prevention. Students had a lecture where their instructor gave them an introduction to first aid and accident prevention. Later, students chose one of the most common home accidents in small groups and made an infographic intended for patient education with key points for accident prevention and safety promotion. On day two, students learned about the triage system and had a self-directed group simulation exercise. Students watched a pre-recorded simulated car accident that resulted in 7 victims. After watching the video, students formed small groups and performed a triage exercise, explaining their reasoning in victim classification using the triage system. The third day included a lecture on CPR technique and practice. Students had to use a home-made CPR mannequin to practice chest compressions. They used a $2 \mathrm{~L}$ plastic bottle, wrinkled paper, rubber bands, and a t-shirt to make their own mannequins. After the lecture and explanatory videos, the instructor gave a CPR demonstration so students could see the live CPR technique and answer any clarifying questions. Afterward, the whole group had a chance to practice the technique at home while the instructor gave feedback to improve their chest compressions. Finally, students made a video while performing CPR on their home-made mannequins. Students had lectures on psychological first aid and a role-playing activity using a clinical vignette with peers and instructors on day four. They also had a plenary question and answer session with experts on psychological first aid. On the last day, students had a final activity where they reflected on their newly acquired abilities and made a report with evidence of their learning (pictures, faculty feedback, etc) that showed their freshly acquired competencies. Figure 1 summarizes the main events of our educational intervention. 


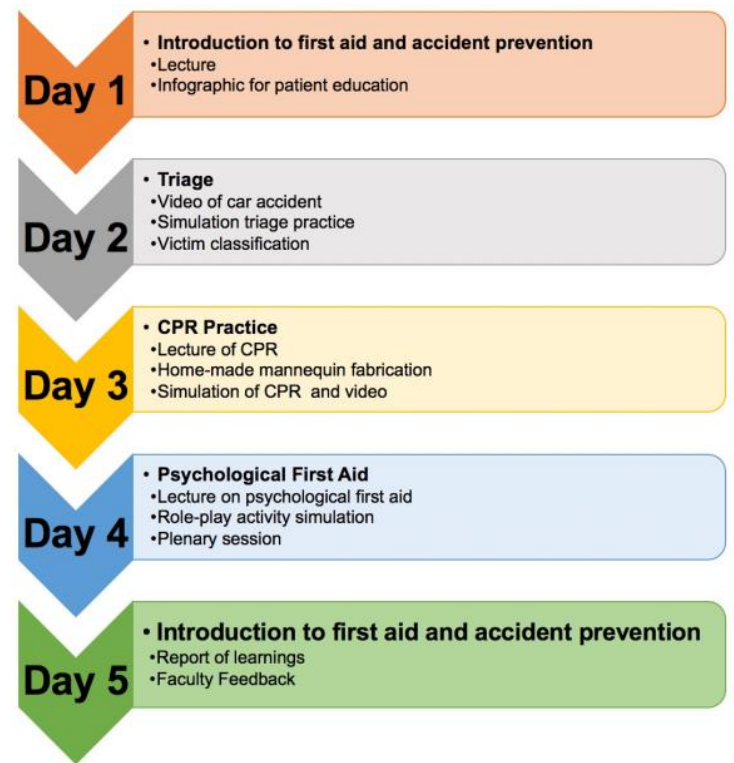

Figure 1: Description of the methodological procedures of the educational intervention.

\section{Evaluation Instrument}

Students answered a questionnaire prior to beginning First Aid Week and then answered it again at the end. The pre-test included twelve items inquiring about their perception regarding their current knowledge or abilities on accident prevention, CPR, psychological first aid, and TRIAGE. Some of the other items were about self-perception of their strengths and weaknesses, and about collaboration and teamwork. The post-test included the same twelve elements and inquired about their improvement and changes in knowledge and abilities after First Aid Week. The questionnaire included a final item where students were to describe in their own words what they learned throughout the week. This was a mixed study, both quantitative, with a pre-test and post-test (Cronbach alpha 0.93 and 0.97), and qualitative. The difference between expectations (pre-test) vs. achievements (post-test) was analyzed with Expectation Confirmation Theory (Olivares et al., 2019), which classifies results as positive confirmation (+DC), confirmation (C), and negative confirmation (-DC). A 5-point Likert scale was used.

\section{Results}

Our overall results showed significant improvements from pre-test to post-test in all of the three evaluated areas $(\mathrm{p}<0.05)$. These changes are represented in Figure 2. 


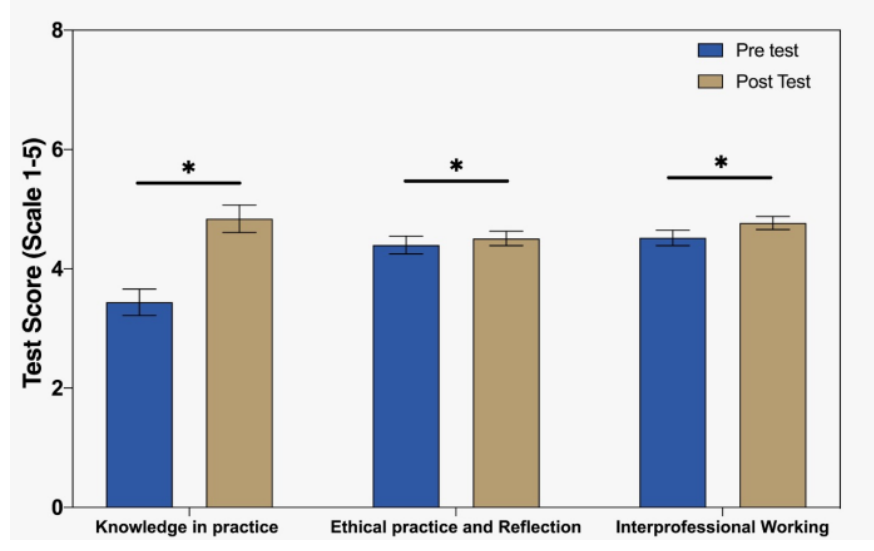

Figure 2: Comparison between pre-test and post-test results

As shown before, knowledge in practice was the most impacted evaluated area by our intervention. This area was evaluated by a series of items shown in Table 1, in which all had significant improvements after the given intervention. These results reflect that medical students acquired adequate skills to act against an accident as first responders, perform basic rescue labor, and apply the principles from psychological first aid in the context of different emergent scenarios.

Table 1: First Aid Week questionnaire - Knowledge in practice

\begin{tabular}{|c|c|c|c|c|}
\hline Pre-Test Question & $\begin{array}{l}\text { Pre-Test } \\
\text { Mean }( \pm \mathrm{SD})\end{array}$ & Post-Test Question & $\begin{array}{l}\text { Post-Test } \\
\text { Mean }( \pm S D)\end{array}$ & $P$ value \\
\hline $\begin{array}{l}\text { I take action against an accident, } \\
\text { performing rescue labor to } \\
\text { stabilize the patients' immediate } \\
\text { life-threatening conditions }\end{array}$ & $3.19( \pm 0.92)$ & $\begin{array}{l}\text { This week has helped me to } \\
\text { know how to act against an } \\
\text { accident as a first responder. To } \\
\text { stabilize patients' immediate } \\
\text { life-threatening conditions. }\end{array}$ & $4.83( \pm 0.83)$ & $\begin{array}{l}<0.0001 \\
*\end{array}$ \\
\hline $\begin{array}{l}\text { I perform basic rescue actions } \\
\text { according to the current } \\
\text { International Guidelines (BLS, } \\
\text { choking and suffocation) }\end{array}$ & $2.85( \pm 1.04)$ & $\begin{array}{l}\text { This week has allowed me to } \\
\text { perform basic rescue labor } \\
\text { according to the International } \\
\text { Guidelines (BLS, choking and } \\
\text { suffocation) }\end{array}$ & $4.81( \pm 0.31)$ & $\begin{array}{l}<0.0001 \\
*\end{array}$ \\
\hline $\begin{array}{l}\text { I assess basic emotional aspects } \\
\text { from an emergency }\end{array}$ & $3.62( \pm 1.15)$ & $\begin{array}{l}\text { This week has helped me to } \\
\text { assess the basic emotional } \\
\text { aspects from an emergency }\end{array}$ & $4.85( \pm 0.77)$ & $\begin{array}{l}<0.0001 \\
*\end{array}$ \\
\hline $\begin{array}{l}\text { I guide others about the decisions } \\
\text { and actions to prevent emergency } \\
\text { situations }\end{array}$ & $3.67( \pm 1.22)$ & $\begin{array}{l}\text { This week has allowed me to } \\
\text { guide others about the } \\
\text { decisions and actions to prevent } \\
\text { emergency situations }\end{array}$ & $4.85( \pm 0.89)$ & $\begin{array}{l}<0.0001 \\
*\end{array}$ \\
\hline
\end{tabular}

Data is represented as the mean of each item $( \pm$ SD). Statistically significant differences are marked with an asterisk $\left({ }^{*} \mathrm{p}<0.05\right)$. Abbreviations: BLS: Basic Life Support. 
The following two domains of the Interprofessional Capability Framework evaluated in the questionnaire were Ethical practice and Reflection. This part of the questionnaire included 5 more items shown in Table 2, that represent the self-evaluation students made before and after the week considering their strengths and weaknesses. The results suggest that this immersive week helped students recognize their strengths and develop their life project.

Table 2: First Aid Week questionnaire - Ethical practice and Reflection

\begin{tabular}{|l|l|l|l|l|}
\hline Pre-Test Question & $\begin{array}{l}\text { Pre-Test Mean } \\
( \pm \text { SD })\end{array}$ & Post-Test Question & $\begin{array}{l}\text { Post-Test } \\
\text { Mean }( \pm \text { SD })\end{array}$ & P value \\
\hline I recognize my strengths. & $4.39( \pm 0.67)$ & $\begin{array}{l}\text { This week helped me } \\
\text { recognize my strengths. }\end{array}$ & $4.59( \pm 0.77)$ & $<.001^{*}$ \\
\hline I accept myself as I am. & $4.31( \pm 0.91)$ & $\begin{array}{l}\text { This week helped me } \\
\text { accept myself as I am. }\end{array}$ & $4.18( \pm 1.09)$ & 0.15 \\
\hline $\begin{array}{l}\text { I know my areas of } \\
\text { gpportunities to achieve my } \\
\text { goals. }\end{array}$ & $4.46( \pm 0.60)$ & $\begin{array}{l}\text { This week helped me } \\
\text { identify my areas of } \\
\text { opportunity to achieve } \\
\text { my goals. }\end{array}$ & $4.57( \pm 0.81)$ & 0.08 \\
\hline $\begin{array}{l}\text { I would like to learn about } \\
\text { ethics and the common } \\
\text { good. }\end{array}$ & $4.69( \pm 0.60)$ & $\begin{array}{l}\text { I learned about ethics } \\
\text { and the common good. }\end{array}$ & $4.70( \pm 0.77)$ & 0.94 \\
\hline $\begin{array}{l}\text { I have a determined life } \\
\text { project. }\end{array}$ & $4.05( \pm 0.46)$ & $\begin{array}{l}\text { This week helped me } \\
\text { develop my life project. }\end{array}$ & $4.47( \pm 0.91)$ & $<.001 *$ \\
\hline
\end{tabular}

Data is represented as the mean of each item $( \pm$ SD). Statistically significant differences are marked with an asterisk $(* \mathrm{p}<0.05)$.

The last domain evaluated in our intervention was Interprofessional working. The series of items used to evaluate this dimension are shown in Table 3. Results strongly suggest that there was good teamwork and collaboration throughout the week.

Table 3: First Aid Week questionnaire - Interprofessional working

\begin{tabular}{|l|l|l|l|l|}
\hline Pre-Test Question & $\begin{array}{l}\text { Pre-Test Mean } \\
( \pm \text { SD })\end{array}$ & Post-Test Question & $\begin{array}{l}\text { Post-Test Mean } \\
( \pm \text { SD })\end{array}$ & P value \\
\hline $\begin{array}{l}\text { In general, team members } \\
\text { that I work with know well } \\
\text { their roles and tasks. }\end{array}$ & $4.33( \pm 0.67)$ & $\begin{array}{l}\text { Team members that I } \\
\text { worked with knew } \\
\text { well their roles and } \\
\text { tasks. }\end{array}$ & $4.77( \pm 0.70)$ & $<.001^{*}$ \\
\hline $\begin{array}{l}\text { Teams where I participate in } \\
\text { have effective methods for } \\
\text { decision making. }\end{array}$ & $4.34( \pm 0.61)$ & $\begin{array}{l}\text { The team I } \\
\text { participated in during } \\
\text { First Aid Week used } \\
\text { effective methods for } \\
\text { decision making. }\end{array}$ & $4.73( \pm 0.72)$ & $<.001 *$ \\
\hline
\end{tabular}




\begin{tabular}{|l|l|l|l|l|}
\hline $\begin{array}{l}\text { I make a commitment to } \\
\text { actively collaborate with my } \\
\text { teammates when the activity } \\
\text { demands it. }\end{array}$ & $4.89( \pm 0.18)$ & $\begin{array}{l}\text { My peers think I } \\
\text { collaborated actively } \\
\text { with the group when } \\
\text { the activity demanded } \\
\text { it. }\end{array}$ & $4.79( \pm 0.66)$ & $<.001 *$ \\
\hline
\end{tabular}

Data is represented as the mean of each item $( \pm$ SD). Statistically significant differences are marked with an asterisk $(* \mathrm{p}<0.05)$.

There was also an analysis on the narrative comments of students about first aid week. Students were able to express in their own words what they learned throughout the week on the last item of the questionnaire. The most common feedback from students was regarding their newly acquired knowledge on the CPR technique. As health care professionals, they knew this was an important part of their training and in learning, so they realized how important it is for everyone to know about it. Student A said: "It made me realize the importance of people knowing the basics of prevention and first aid in order to be able to act timely." Another repeated comment was that the week-long training prepared them to act in an emergency and gave them confidence in doing so. Student B said, "It gave me a lot of confidence to act and help a person in a critical situation". Student C stated, "I learned how to act in an emergency situation, and it gave me the confidence to help whenever it is needed." Collaborative work was also mentioned in the questionnaire, student D said: "I learned how to work from distance in an efficient and collaborative manner". In general, the most repeated comment was regarding their new knowledge on first aid and how this was going to allow them to help whenever it was needed.

\section{Discussion}

First aid basic training can be a challenge regarding design and implementation in first-year medical and health sciences students, especially in remote settings. Traditional first aid courses usually involve the use of special equipment for face-to-face training (Tan et al., 2010). Our initiative was completely remote and involved students using materials they might have at home. Additionally, a real-life TRIAGE simulation exercise was substituted by a pre-recorded video of an accident with victims. The video involved actors with simulated injuries, fractures, and altered mental status. The psychological first aid role-playing activity involved several clinical vignettes relevant to students, such as emotional crises during the pandemic or involving struggling students (Minihan et al., 2020). The portion of First Aid Week dedicated to prevention involved students designing an infographic. Peers and instructors provided feedback on the educational material and provided recommendations to make it more understandable and relevant for the general audience. Peer feedback can be a powerful tool for students to perceive it as appropriate and move to action (Lerchenfeldt et al., 2019).

Besides the challenge of creating a remote first aid basic training, the program was held using an interprofessional approach. Students of medical, dentistry, nutrition, clinical psychology, and biosciences programs worked together in groups throughout the week. This allowed us to foster a cooperative rather than competitive learning and enhance their educational experience. (Khabaz et al., 2016) They were also able to gain different perspectives on patient care and practiced their communication and teamwork skills (Burgess et al., 2020). 
The questionnaire results, both on the quantitative and qualitative part, show that students consider their first aid skills to have considerably improved. Having these results in a remote learning environment with traditionally physically hands-on skills shows promising new ways of designing remote learning experiences for students. Another thing to consider is that this was an interdisciplinary activity in which all health professions participated, learned, and developed abilities. Interprofessional collaboration can be a good opportunity for students to go beyond their traditional thinking and develop new skills (Green and Johnson, 2015). Results on interprofessional working were also promising because they were achieved through online learning as well. Although this intervention proved to be useful for students, a further similar experience should be implemented in the future for students to retain their newly gained knowledge (Das and Elzubeir, 2001). The scope for further research is to make this a longitudinal study and follow students through their whole professional formation.

\section{Conclusion}

First aid training in young health professions students should not stop during the pandemic or for any other reason. Alternate design strategies can be implemented for students to acquire first aid knowledge and skills, such as TRIAGE, CPR, psychological first aid and accident prevention. Remote First Aid Week proved to be a relevant and practical approach for students to learn in an immersive, hands-on, and interdisciplinary way, all from home. This experience sets a precedent to keep exploring interdisciplinary focused training.

This remote first aid training week was a challenge for both students and teachers. Faculty benefited from this online teaching format because they acquired practice and experience to teach skills remotely. This distance-learning experience was a way of ensuring that students acquired first aid knowledge and skills even with pandemic related limitations. It benefited students since even though they are currently receiving most of their education in an online format, they are part of the healthcare team and must be ready to act in basic emergency situations starting from their first years of health formation. In addition to this, they learned that interdisciplinary work can also be achieved through this format. The school administrators were benefited as well because the entire week was held using very few resources, discovering a new way of teaching first aid skills. Future implications for schools are to change the paradigm that first aid training must be face-to-face. First aid training should not stop with this one-week experience, but it is a reasonable, safe, and efficient way to start.

\section{Acknowledgements}

Leaders, academic advisors and program directors of the Academic Societies of Tecnológico de Monterrey, Escuela de Medicina y Ciencias de la Salud.

\section{References}

Burgess, A., Kalman, E., Haq, I. et al. (2020) Interprofessional team-based learning (TBL): how do students engage?. BMC Med Educ 20(118) . https://doi.org/10.1186/s12909-020-02024-5

Canady, V.A. (2019), Mental Health First Aid campaign to support first responders. Mental Health Weekly, 29: 6-6. https://doi.org/10.1002/mhw.31780 
Cherit, G., Luna-Ceron, E., Vichi-Lima, L., Romo, S., Hernández, R., Farah, A., . . Gutiérrez, L. (2021). Massive Digital Training for the Acquisition of Theoretical Knowledge About COVID-19 in Mexico. Investigación en Educación Médica, 10, 50-60. doi:10.22201/fm.20075057e.2021.37.20269.

Das, M., Ezubeir, M. (2001) First Aid and Basic Life Support Skills Training Early in the Medical Curriculum: Curriculum Issues, Outcomes, and Confidence of Students, Teaching and Learning in Medicine: An International Journal, 13(4), 240-246, DOI: 10.1207/S15328015TLM1304_05

Dedeilia, A., Sotiropoulos, M. G., Hanrahan, J. G., Janga, D., Dedeilias, P., \& Sideris, M. (2020). Medical and Surgical Education Challenges and Innovations in the COVID-19 Era: A Systematic Review. In vivo (Athens, Greece), 34(3 Suppl), 1603-1611. https://doi.org/10.21873/invivo.11950

Eisenburger, P., Safar, P. (1999) Life supporting first aid training of the public - review and recommendations. Resuscitation, 41(1), 3-18. DOI: https://doi.org/10.1016/S0300-9572(99)00034-9

Gonzales Zamora, J., Alave, J., De Lima Corvino, D., \& Fernandez, A. (2020). Videoconferences of Infectious Diseases: An educational tool that transcends borders. A useful tool also for the current COVID-19 pandemic.

Gordon, F., \& Walsh, C. (2005) A Framework for Interprofessional Capability: Developing Students of Health and Social Care as Collaborative Workers. Journal of Integrated Care, 13(3), 26-33. Doi: $10.1108 / 14769018200500023$

Green, B. N., \& Johnson, C. D. (2015). Interprofessional collaboration in research, education, and clinical practice: working together for a better future. The Journal of chiropractic education, 29(1), 110. https://doi.org/10.7899/JCE-14-36

Harkins, K. (2020). CPR in 30 minutes. University of Minnesota. Retrieved February $12^{\text {th }}$ from https://med.umn.edu/dom/department-medicine-events.

Ingrassia, L, Ragazzoni L, Carenzo L, Colombo D, Ripoll Gallardo A, Della Corte F. (2015) Virtual reality and live simulation: a comparison between two simulation tools for assessing mass casualty triage skills. Eur J Emerg Med. 22(2):121-127. doi: 10.1097/MEJ.0000000000000132.

Khabaz Mafinejad, M., Ahmady, S., Soltani Arabshahi, S. K., \& Bigdeli, S. (2016). Interprofessional education in the integrated medical education and health care system: A content analysis. Journal of advances in medical education \& professionalism, 4(3), 103-110.

Lerchenfeldt, S., Mi, M. \& Eng, M. (2019) The utilization of peer feedback during collaborative learning in undergraduate medical education: a systematic review. BMC Med Educ 19(321) https://doi.org/10.1186/s12909-019-1755-z

Magnavita, N., Sacco, A., Nucera, G., Chirico, F., (2020) First aid during the COVID-19 pandemic, Occupational Medicine, 70 (7), 458-460, https://doi.org/10.1093/occmed/kqaa148.

Mian, A., \& Khan, S. (2020). Medical education during pandemics: a UK perspective. BMC Medicine, 18(1), 100. https://doi.org/10.1186/s12916-020-01577-y

Minihan, E., Gavin, B., Kelly, B., \& McNicholas, F. (2020). COVID-19, mental health and psychological first aid. Irish Journal of Psychological Medicine, 37(4), 259-263. doi:10.1017/ipm.2020.41

Nelson, M. (1982), A first aid and CPR course for first-year medical students. Medical Education, 16: 7-11. https://doi.org/10.1111/j.1365-2923.1982.tb01211.x

NHCPS. (2020). Saving Lifes Initiative. NHCPS. Retrieved February $12^{\text {th }}$ from https://nhcps.com/how-to-safely-get-cpr-training-during-the-coronavirus-pandemic/.

Olivares, S.L., Adame, E., Treviño, J.I., López, M.V. and Turrubiates, M.L. (2019), "Action learning: challenges that impact employability skills", Higher Education, Skills and Work-Based Learning, 10(1), pp. 203-216. https://doi.org/10.1108/HESWBL-07-2019-0097

Pande, S., Pande, S., Parate, V., Pande, S., Sukhsohale, N. (2014). Evaluation of retention of knowledge and skills imparted to first-year medical students through basic life support training. Advances in Physiology Education, 38 (1), 42-45. https://doi.org/10.1152/advan.00102.2013 
Perkins, G., Hulme, J., Shore, H., Bion, J. (1999) Basic life support training for health care students, Resuscitation, 41 (1), 19-23, https://doi.org/10.1016/S0300-9572(99)00037-4

Sapp, R., Brice, J., Myers, J., \& Hinchey, P. (2010). Triage Performance of First-Year Medical Students Using a Multiple-Casualty Scenario, Paper Exercise. Prehospital and Disaster Medicine, 25(3), 239-245. doi:10.1017/S1049023X00008104

Shah, K., Bedi, S., Onyeaka, H., Singh, R., \& Chaudhari, G. (2020). The Role of Psychological First Aid to Support Public Mental Health in the COVID-19 Pandemic. Cureus, 12(6), e8821. https://doi.org/10.7759/cureus.8821

Tan, E., Hekkert, K., Van Vugt, A., Biert, J. (2010) First Aid and Basic Life Support: A Questionnaire Survey of Medical Schools in the Netherlands, Teaching and Learning in Medicine: An International Journal, 22(2), 112-115, DOI: 10.1080/10401331003656538

Tan, E., Severien, I., Metz, J., Berden, H., Biert, J. (2006) First aid and basic life support of junior doctors: A prospective study in Nijmegen, the Netherlands, Medical Teacher, 28(2), 189-192. DOI: http://dx.doi.org/10.1080/01421590500312847

WHO (2008) World report on child injury prevention: Summary. Retrieved from: https://www.who.int/violence_injury_prevention/child/injury/world_report/report/en/\#: :text=The\%2 0report $\% 20$ documents $\% 20$ the $\% 20$ magnitude,to\%20improve $\% 20$ child $\% 20$ injury $\% 20$ prevention. 